\title{
An Analysis of the Relationship Between Equity and Composite Index in Bursa Malaysia
}

\author{
Fauziah Mahat, Aminah Shari*, Ahmed Mohamed Dahir \\ Department of Accounting and Finance, Faculty of Economics and Management, Universiti Putra Malaysia
}

\begin{abstract}
This paper examines the relationship between sectoral equity and composite index in Bursa Malaysia. The relationship between equity returns and composite index is investigated using correlation-based on Ordinary Least Square (OLS) and signal decomposition techniques based on wavelet analysis. The paper uses daily data from 1999 to 2019. The OLS result indicated that majority of sectoral equity have a higher correlation with the composite index except in tin and mining sector. The wavelet analysis indicates a majority of sectors are strongly co-move. For all indices, there are lead/lag relationships between the indices except for industrial, plantation, tin mining and trade, and services. The findings have important implications for helping individual and institutional investors to understand the co-movement of equity sectors and then formulate policy measures that encourage better portfolio diversification.
\end{abstract}

Keywords: Co-Movement, Wavelet Analysis, Continuous Wavelet Transform, Portfolio Choice, Investment Decision

JEL Classification: D53, C58

Paper Type: Research

\section{INTRODUCTION}

The importance of correlation is a fundamental input for asset allocation decisions as it determines the diversification benefits within an investment portfolio (Cascino, 2017). Hence, the tradeoff between risk and returns plays an important role in making investment decisions. Investors attempt to reduce the risk of their portfolio by diversifying their asset holdings so that there are sufficiently unrelated to each other. In order to achieve portfolio diversification benefits, the tradeoff between risks and returns plays an important role in making investment decisions (Anand, Li, Kurosaki and Kim, 2016). Investors attempt to reduce the risk of their portfolio by diversifying their asset holdings so that they are sufficiently unrelated to each other. Also, it is possible that investors would allocate a substantial portion of their funds toward sectoral indices in order to seek a higher return.

*Corresponding author: E-mail: f_mahat@upm.edu.my 
Consistent with portfolio theory, investing in less correlated assets will result in a greater diversification gain (Ahmed \& Huo, 2018).

The purpose of this paper is to examine the co-movement of the Malaysian sectoral equities with a composite index. For this purpose, the study applies wavelet coherent to investigate the interdependence between sectoral equities market changes significantly in time and varies across different investment horizons. This approach distinguishes between different type of investor behaviour with different investment horizons. This would provide additional insight to investors, particularly retail and institutional investors, financial institutions, analyst, to assess the future trend of the market as well as a useful guideline for portfolio formation and investment decisions. The study follows the wavelet method developed by Graham and Nikkinen (2011) to examine the co-movements between sectoral equities and stock return.

The article is organized as follows. Section 2 briefly reviews the relevant literature on co-movement. Section 3 describes the wavelet coherence used for the estimation of sectoral correlation in the time-frequency domain. The used data are detailed in section 4. Section 5 presents and discusses the empirical results and section 6 concludes.

\section{LITERATURE REVIEW}

Co-movement of financial assets has been investigated in numerous influential studies. The aim is to understand the interdependence of two or more financial markets or assets. However, recent studies on co-movement analysis have concentrated on an aggregate level without focusing on sector level analysis. Specifically, studies with methodologies similar to this study except in Benlagha (2014) for French bond portfolio only and Erdogan, Tata, Karahasan and Sengoz (2013) for stock and maritime sector index; the latter studies of Chen, Chen and Tseng (2017) for healthcare sector index and US, UK and Germany stock market, el Alaoui, Dewandaru, Azhar Rosly and Masih (2014) for Dubai financial stock market index and Aloui, Hammoudeh and Hamida (2015) for Islamic Stock and Sukuk have all remarked that the markets in question experiences a process of comovement in varying degrees. An associated finding is that the benefits of portfolio diversification vary across frequencies and time. The empirical studies have stated that the high level of co-movement related to a lower degree of diversification benefits. Therefore, the strong correlation between the sectors under investigation indicated lower diversification benefits.

Several studies demonstrate the limited diversification benefits of the stock market. Marfatia (2017), Mensi, Hammoudeh and Kang (2017), Mimouni, Charfeddine and AlAzzam, (2016) investigate the different geographical region correlation. Researchers have mentioned significant co-movement between developed markets and emerging markets (Buchanan, English \& Gordon, 2011; Marfatia, 2017), developed and BRICS stock market (Mimouni et al., 2016; Mohamed Dahir, Mahat, Ab Razak \& Bany-Ariffin, 2018) and Gulf Cooperation Council countries (Mensi, Hammoudeh and Kang, 2017). However, the measure does not capture the level of portfolio diversification implication as they measure inter-market (Mensi, Hammoudeh and Kang, 2017 and (Buchanan et al., 2011). Therefore, as highlighted in Buchanan et al. (2011), it is possible to investigate effects of diversification in capital market investment on a different type of asset class and improve the investor's portfolio decision (Mensi, Hammoudeh, Al-Jarrah, Sensoy and Kang, 2017). This shows, there is a need to analyze the co-movement of stock return and volatility at the sectoral level, which is relatively less explored in the literature.

Relatively few studies have examined co-movements using sectoral returns, and most of these employed individual sector analysis. Chen, Chen and Tseng (2017) examined health care sector index; Ben-Salha, Hkiri and Aloui (2018) and Vacha and Barunik (2012) 
US energy sector; Reboredo and Uddin (2016) metal sector; Hiang Liow (2012) and Liow and Angela (2017) real estate sector, Mensah and Premaratne (2017) banking sector and Pal and Mitra (2019) automobile sector. In fact, this paper emphasizes that previous studies on co-movement of specific sector suggesting conflicting findings. For example, Hargis and Jianping (2006) show that a shift in factor importance from country to industry. Rehman and Shah (2016) confirm the sector varying coefficients, indicating the sectoral riskiness varies, suggesting for future sectoral stock market investment portfolio (Poynter, Winder and Tai, 2013).

The paper to apply wavelet analysis method in this context was Ben-Salha et al. (2018). They find significant co-movement of energy consumption with the US industrial sector under the high-frequency band. Chen et al. (2017) used the same methodology considering the cross-market correlation of the health care sector. They applied three different approaches of wavelet analysis and find that the health care sector in the US has a statistically significant only for the long run. Therefore, the investors can follow the health care price pattern of US to predict the future price of health care stock price.

Graham and Nikkinen (2011) first proposed the use of wavelets to estimate the comovement of international stock markets from European countries. They estimate the return of each stock annually for three-dimensional wavelet coherency approach using weekly returns for the period January 1999 to October 2009 for stock that was in the Morgan Stanley Capital International. They find that the co-movement is stronger at higher frequencies. Kallberg and Pasquariello (2008) examine the co-movement of US stock market indexes. Their data set consists of 82 industry indexes from January 1976 through December 2001. They also examine the co-movement among the indices at a weekly level by using FGLS rolling regressions. However, they find the contradict finding that comovement of stock markets changes is not significantly in time. Among the studies that explore sector wise-stock return, Poynter et al. (2013) suggest that there is an interrelationship between different sector indices in the US.

Recent research that demonstrates the empirical support that investment horizon among investors matters in credit and stock markets is found in Shahzad, Ferrer, Hammoudeh and Jammazi (2018) and Shahzad, Nor, Sanusi and Kumar (2017), inequity and bond market (Sakemoto, 2018). However, the literature reveals a deficiency. Wavelets estimates of return did not consider comprehensive sector-level analysis as evidence on the previous finding limited to developing countries and individual sector level only.

In summary, this paper fills an important gap in the importance of capturing differences in investor horizons. Thus, there is a need to be made between short-term, long-term investors. The empirical results have practical implications for portfolio managers in asset allocation to different sectors and risk management. A wavelet approach for estimating market return has been utilized in this study. Wavelet analysis makes it possible to identify regions in a time-frequency space where two stock market are co-vary, indicating the benefits of portfolio diversification are decrease.

\section{METHODOLOGY AND DATA}

In this section, the study implements the theoretical results on the wavelet coherence analysis and correlation-based on Ordinary Least Square (OLS). The study employed wavelet transformations to examine the time-varying and time-scale dependent return comovements between the sample indexes. The study uses wavelet coherence to identify the co-movement and the lead-lag relationship between multi-asset classes and market return. The analysis of the correlation between two CWT is generally known as wavelet coherence. Accordingly, the lead-lag relationship is important in term of identifying the 
cause-effect relationship between the selected indexes. The main reason for using wavelet coherence analysis is to address the time-varying property of co-movement in different holding periods (Daubechies, 1992). On the other hand, the benefit of the wavelet analysis is it can perform a multiresolution analysis. That is, it allows to analyses the data at different scales at the same time

\subsection{Data}

The data used in this study consists of sectoral equity indices and stock market index. The paper uses daily data that ranges from 5 February 1999 to 6 February 2019 extracted from Thomson Reuters DataStream. The sectors breakdown is according to the Securities Commission of Malaysia classification. Thus, the overall sector for stock market consists of fourteen sectors namely construction, consumer product and services, energy, financial services, health care, industrial products and services, plantation, property, real estate investment trust (REITs), SPAC, technology, telecommunication and media, transportation and logistics and utilities. The sample sectors consist of the consumer product (LCONP), construction (LCONS), finance (LFIN), industrial (LIND), industrial product (LINDP), plantations (LPLNT), properties (LPRO), tin and mining (LTNM) and trade and services (LTNS).

In addition, the used sector portfolios would minimize the impact of any survivorship bias or look-ahead bias. In addition, sector portfolios are useful in this context because of the wide variability in business cycles and risk properties across the firms over these sectors (Faff, Hillier and Hillier, 2000). The study used the daily frequency data due to the following reasons, first, complete information on the dynamic conditional correlation than the monthly data. More specifically, using the daily frequency data is more useful for investors to build an optimal portfolio and generate economic gains. On the other hand, Mensi, Hammoudeh and Kang (2017) document that a daily data model is a better predictor of returns than a monthly data model.

\subsection{Model Specification}

In order to identify the dependence between two time series in the time and frequency domains, there are three approaches that can be applied. These include cross- wavelet power, wavelet power spectrum and cross- wavelet transform (Graham and Nikkinen, 2011). The wavelet power spectrum (WPS) measures the variance of single wavelet that detects and measures the relations between two-time series; the cross-wavelet power assesses the covariance of the time series while the cross- wavelet transform can control the dependences of frequency and time between two-time series. According Aguiarconraria et al. (2008) defined wavelet coherence (WTC) as "the ratio of the cross-spectrum to the product of the spectrum of each series, and can be thought of as the local correlation (both in frequency and time), between two-time series". The wavelet coherence is expressed in terms coefficient of correlation of time-frequency space. We define the wavelet coherence as determined by Equation [1]:

$$
R_{n}^{2}(s)=\frac{\mid S\left(\left.s^{-1} W_{n}^{X Y}(s)\right|^{2}\right.}{S\left(s^{-1}\left|W_{n}^{X}(s)\right| \bullet S\left(s^{-1}\left|W_{n}^{Y}(s)\right|^{2}\right)\right.}
$$

Where $R^{2}$ represents for wavelet coherency and $S$ is for a smoothing operator. Interestingly, the value of wavelet coherence ranges from 0 to 1 . It is a localized correlation 
coefficient in time-frequency space and also is a useful technique for analysis of comovements across two-time series. The wavelet coherency can be interpreted similarly to the correlation coefficient suggesting strong dependence when the value is close to 1 and weak dependence when the value is close to 0 . Likewise, the wavelet power spectrum explains the variance of a time series and covariance which capture cross wavelet power between two-time series at each scale or frequency. If the variance of a time series becomes large, the wavelet suggests that the existence of a sizeable power spectrum. The statistical significance of wavelet coherence coefficient is estimated using Monte Carlo simulation, though little is known its theoretical contribution (Torrence and Compo, 1998).

The equity sector return was computed as the first difference of the logarithm of daily indexes times 100. In other words, the formula for equity sector returns can be written as follows:

$$
R_{t}=100 \times \log \left(P_{t} / P_{t-1}\right)
$$

Where $R_{t}$ indicates the stock returns and $P$ represents stock index levels at the time $(t)$ and $(\mathrm{t}-1)$.

\section{EMPIRICAL RESULTS}

In this section, the paper implements the theoretical results on the wavelet coherence analysis. The paper use wavelet coherence to identify the co-movement and the lead-lag relationship between sectoral indices and market return. Accordingly, the lead-lag relationship is important in term of identifying the cause-effect relationship between the selected indexes. The main reason for using wavelet coherence analysis is to address the time-varying property of co-movement in different holding periods (Chen et al., 2017). On the other hand, the benefit of the wavelet analysis is it can perform a multiresolution analysis. That is, it allows to analyze the data at different scales at the same time.

\subsection{Descriptive Statistics}

Table 1 shows the descriptive statistics of returns for sectoral indices and market return. With regard to sectoral indices, it appears that the volatility represented by the standard deviation is the highest for tin and mining sector and the lowest volatility for the consumer product. The average daily returns are relatively small than the standard deviation, but the technology sector indicated the lowest average returns and highest volatility among the selected sectors. The skewness was negative for all selected sectors except in tin and mining sector. The finding in line with the previous study of Mensah and Premaratne (2017) which found the banking sector negatively skewed. As a result, based on JarqueBera statistic, the study rejected the null hypothesis demonstrating that the data were normally distributed in all series. 
Table 1. Statistical Description of Sectoral Indices

\begin{tabular}{lllllll}
\hline Variable & Mean & Std. Dev. & Skewness & Kurtosis & Jarque-Bera & Observations \\
\hline KLCl & 0.007 & 0.353 & -0.659 & 14.277 & $27356.990^{* * *}$ & 5093.000 \\
LCONP & 0.012 & 0.283 & -0.583 & 12.959 & $21334.080^{* * *}$ & 5093.000 \\
LCONS & -0.003 & 0.563 & -1.093 & 19.397 & $58071.370^{* * *}$ & 5093.000 \\
LFIN & 0.009 & 0.409 & -0.390 & 13.465 & $23369.250^{* * *}$ & 5093.000 \\
LIND & 0.008 & 0.349 & -0.422 & 14.750 & $29450.150^{* * *}$ & 5093.000 \\
LINDP & 0.006 & 0.377 & -0.789 & 13.300 & $23043.220^{* * *}$ & 5093.000 \\
LPLNT & 0.013 & 0.426 & -0.357 & 18.804 & $53108.020^{* * *}$ & 5093.000 \\
LPRO & -0.001 & 0.467 & -0.566 & 14.835 & $29996.540^{* * *}$ & 5093.000 \\
LTNM & 0.010 & 1.136 & 2.057 & 67.571 & $888369.200^{* * *}$ & 5093.000 \\
LTNS & 0.005 & 0.382 & -0.518 & 14.660 & $29078.530^{* * *}$ & 5093.000 \\
\hline
\end{tabular}

Statistical significance at ${ }^{*} \mathrm{p}<0.05,{ }^{* *} \mathrm{p}<0.01$, and ${ }^{* * *} \mathrm{p}<0.001$.

Standard Deviation (Std. Dev).

\subsection{Correlation Analysis}

The relationship between equity returns and composite index is investigated using correlation-based on Ordinary Least Square (OLS). The paper uses daily data in the period of 1999 to 2019. The OLS result indicated that majority of sectoral equity have a higher correlation with the composite index except in tin and mining sector, as shown in Table 2.

Table 2. Correlation Matrix Analysis

\begin{tabular}{lllllllllll}
\hline & KLCl & LCONP & LCONS & LFIN & LIND & LINDP & LPLNT & LPRO & LTNM & LTNS \\
\hline KLCl & 1 & & & & & & & & & \\
LCONP & 0.721 & 1 & & & & & & & & \\
LCONS & 0.722 & 0.571 & 1 & & & & & & & \\
LFIN & 0.894 & 0.633 & 0.674 & 1 & & & & & & \\
LIND & 0.803 & 0.698 & 0.588 & 0.658 & 1 & & & & & \\
LINDP & 0.775 & 0.643 & 0.677 & 0.696 & 0.701 & 1 & & & & \\
LPLNT & 0.688 & 0.534 & 0.530 & 0.566 & 0.572 & 0.563 & 1 & & & \\
LPRO & 0.712 & 0.623 & 0.726 & 0.691 & 0.586 & 0.733 & 0.545 & 1 & \\
LTNM & 0.243 & 0.244 & 0.256 & 0.239 & 0.206 & 0.268 & 0.205 & 0.290 & 1 & \\
LTNS & 0.938 & 0.648 & 0.688 & 0.788 & 0.783 & 0.727 & 0.592 & 0.704 & 0.240 & 1 \\
\hline
\end{tabular}

\subsection{Wavelet Coherence}

In this section, the paper presents the continuous wavelet analysis to investigate the comovement and lead-lag relationship between sectoral indices and market return. Figure 1 shows the wavelet coherence analysis of sectoral indices and market return. The vertical axis refers to the different holding period represented from scale 1 (one day) up to scale 10 (1024 days). The horizontal axis refers to the time element. The horizontal axis covers study periods from 2002 to 2019, corresponding to 1000 and 5000 (i.e., 2003, 2007, 2011, 2015 and 2019). Next, the study further divides these levels into three holding periods, namely 2- to 64-day scales indicating short term, 64- to 256-day scales indicating medium term, and 256- to 1024-day indicating long term dynamics.

The figure uses a colour code to measure the degree of correlation or co-movement between the pair of indexes. The red colour indicated the warmer regions refers to the two series are highly correlated. Meanwhile, the blue colour indicated the cooler regions refers to that two series are low correlated. The 5 percent significant level was obtained from the Monte Carlo simulations is represented by the curved line.

Next, in order to investigate the lead-lag relationship of sectoral indices and market return, the wavelet coherence phase difference continues to reveal co-movement in index 
pairs through different investment horizons or holding period. Moreover, arrows representing phase differences indicate the direction of interdependence and cause-effect relationship. When the vector arrows pointing to the right, it was indicated that the indexes are in phase (positive correlation), however, when they pointing to the left, it shows that the indexes are out of phase (negative correlation). The results reveal that the majority of sectors strongly co-move.

In addition, the impact changes across low-frequency scales. More specially, the sectors are positively associated with each other. For all indices, there are lead-lag relationships between the indices except for industrial, plantation, tin mining and trade and services. From Figure 1, a phase difference of zero indicating that the sectoral indices and market return move jointly in the same direction, while an out of phase difference indicates that pair series move in the opposite direction.

Based on Figure 1, the co-movement between sectoral indices and market return are positive over time and frequency domains. However, the coherence in the index pair of sectoral indices and market return increases at low-frequency scale (64-256 days and 256 -1024 days), and they were ranging from about 2002 to 2019. Co-movement of sectoral indices and market return shows high coherence in construction, consumer product, finance, industrial, industrial product, plantation, properties and trade and services sectors except in tin and mining sector, the index pair is statistically significant. The correlation between trade and service sector indices and market return demonstrates a significant interdependence exists at all scales namely, the short, medium and long term over 2002 to 2109 , however, the highest level of coherences (co-movement) was recorded at scales ranging from 64 to 1024 days scales from 2002 to 2015. In the trade and service sector index, the arrows point rightward and downward, indicating that the sector index and market return are positively correlated, and sector index lead market returns.

According to Figure 1 (c), (d) and (i), the plots pair of wavelet coherence shows the highest significant co-movement over time and frequency domains. The correlation between finance, industrial and trade and services are relatively stronger for all investment holding period, namely short holding period, medium- and long-term holding period over 2003 to 2015. In the most three significant sectors, the arrows point rightward and downward, indicating that sector returns and market returns are positively correlated, and sector returns lead market returns.

On average, the study noticed that Figure 1 (a), (b) and (e) wavelet coherence reveal that sector returns and market returns show average significant co-movement over time and frequency domains in Malaysia. However, the coherence in the index pair increases at a lower frequency (256-1024 days) during the period of 2003 to 2011 for construction, consumer product and industrial product. The arrows (lead-lag relationship) point rightward and downward at 64-256 days from 2003 to 2015 . Therefore, there is a positive relationship between the index pair, and sector returns lead market returns benchmark.

However, the wavelet coherence of Figure 1(f), (g) and (h), show the least association, indicating no co-movement. There is a significant small blue region both the middle and low scales, but these show that wavelet coherence decreases gradually from higher to lower frequency bands. The lead-lag relationships seem to suggest negative associations and that market return lead sector return. However, the co-movement between sector return and market return are not statistically significant, as shown in Figure 1(h), as the blue colour dominates the area. 


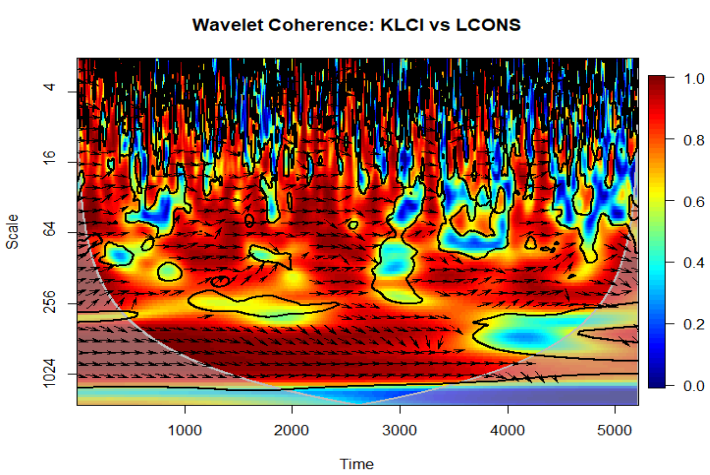

(a) Construction

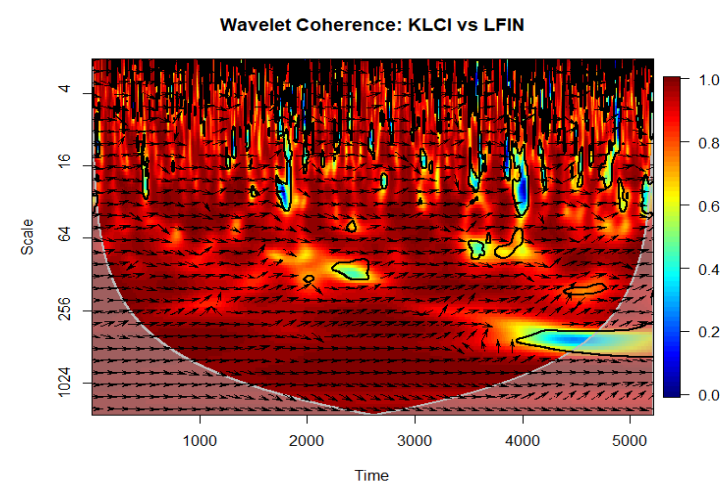

(c) Finance

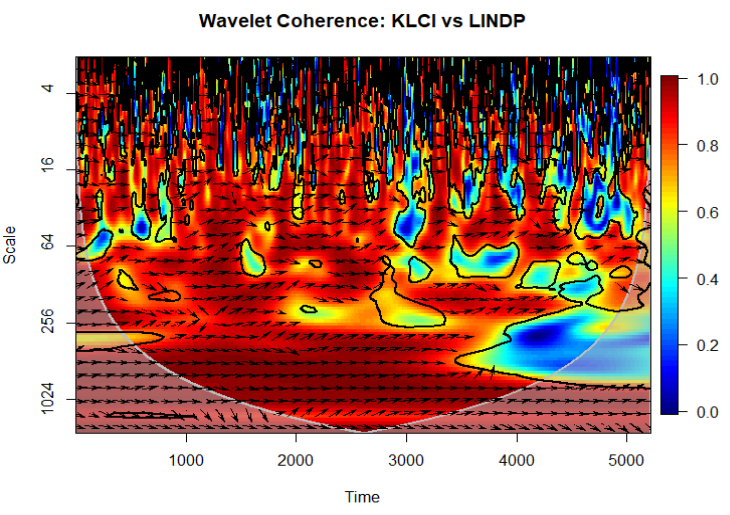

(e) Industrial Product

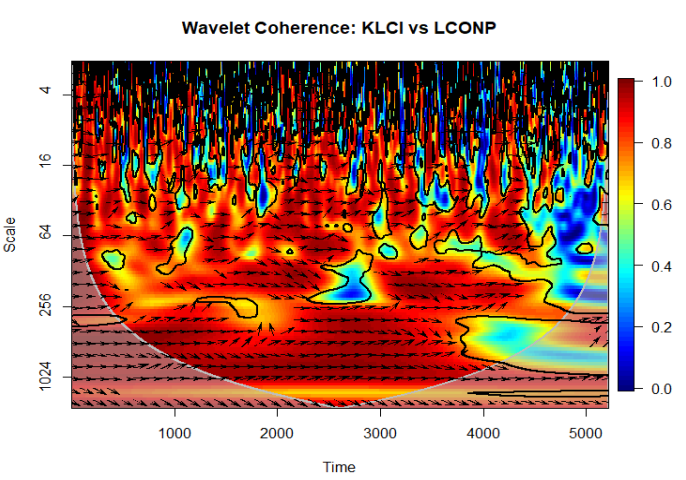

(b) Consumer Product

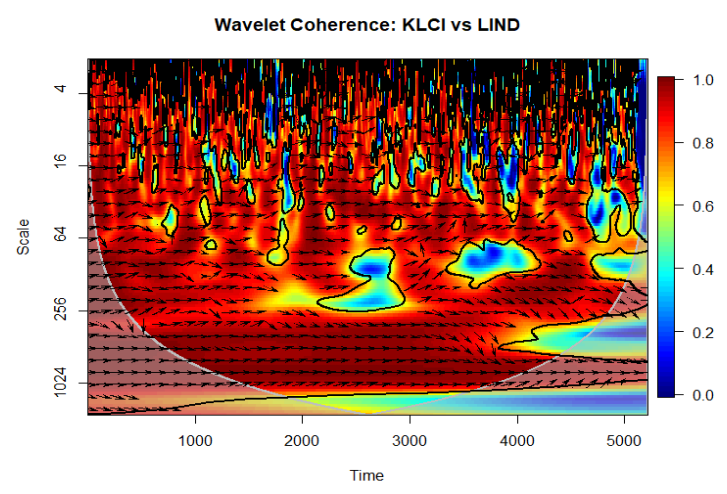

(d) Industrial

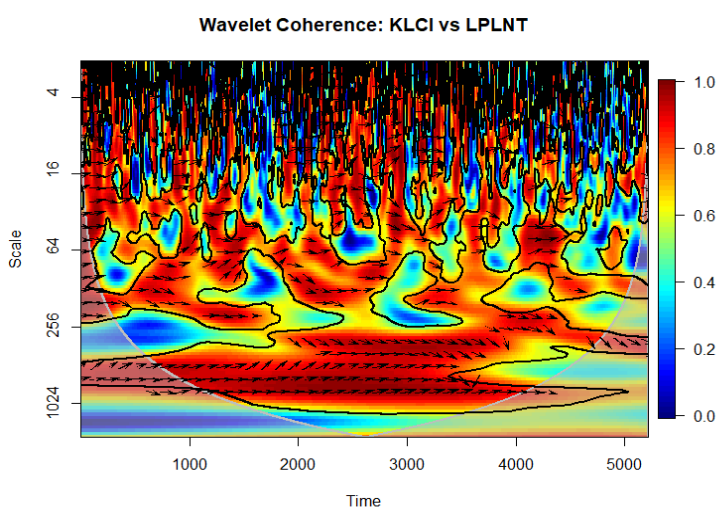

(f) Plantation 


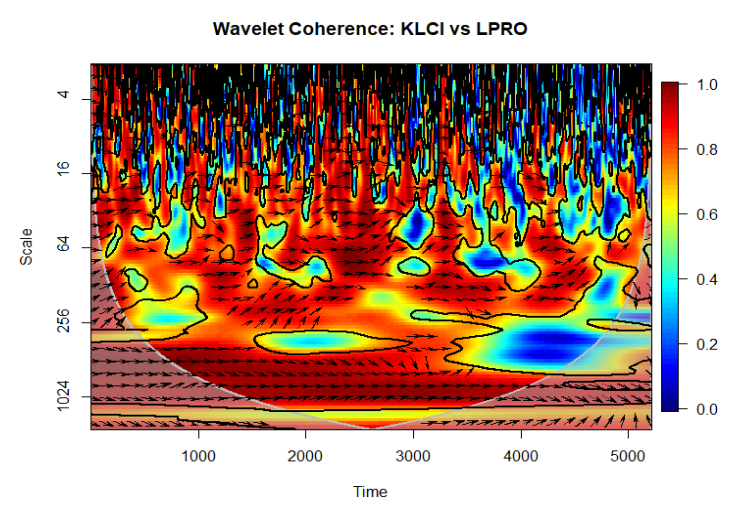

(g) Properties

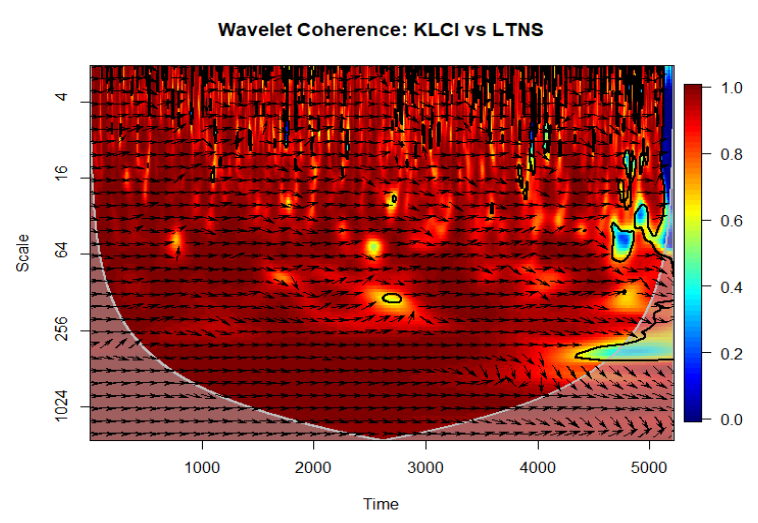

(i) Trade and Services

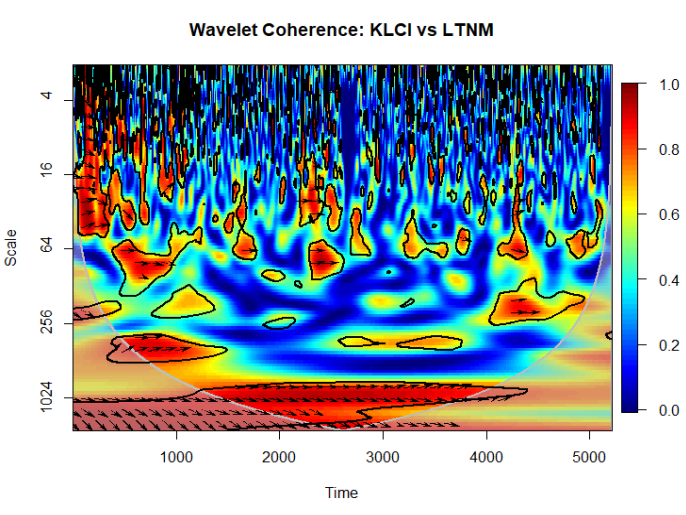

(h) Tin and Mining

\begin{tabular}{|l|l|l|l|l|}
\hline 1000 & 2000 & 3000 & 4000 & 5000 \\
\hline 2003 & 2007 & 2011 & 2015 & 2019 \\
\hline
\end{tabular}

Figure 1. Wavelet coherence for equity sectoral indices and market returns.

The vertical axis is the frequency component, while the horizontal axis is the time component; The thick black contour represents regions at the $5 \%$ level, and the curved black line denotes a cone of influence, which indicates the regions affected by edge effects. Right up and down show in-phase, while left up and down represent out of phase.

\section{CONCLUSION}

Time-frequency domain analysis conducted in this paper can benefits from the portfolio diversification with the sectoral indices in Malaysia. A discussion on the dynamic relationship of return in Malaysian equities among comprehensive sector is rare in the field of finance. This study provides new insight into the co-movement and lead/lag relationship among Malaysian equities sectors from 1999 to 2019. To analyze the issue in details, this study has distinguished the time-frequency relationship between sector return by using continuous wavelet approach.

In general, the study finds positive correlations between the co-movement of sectoral equities and composite index returns. The finding reveals that the majority of sectors strongly co-move. In addition, the impact changes across low-frequency scales. More specially, the sectors are positively associated with each other. 
Further research should examine the co-movement of risk through the co-movement on a sectoral level. Although most of the previous studies have been focusing on the comovement of country-level market indices, much less is known at sector levels. Therefore, a deeper understanding of risk and return behaviour of such equity indices, and, in particular, their determinants, can help sustain the increasing interest of investors in the industry.

\section{REFERENCES}

Aguiar-Conraria, L., Azevedo, N., \& Soares, M. J. (2008). Using wavelets to decompose the time-frequency effects of monetary policy. Physica A: Statistical Mechanics and its Applications, 387(12), 2863-2878.

Ahmed, A. D., \& Huo, R. (2018). China-Africa financial markets linkages: Volatility and interdependence. Journal of Policy Modeling, 40(6), 1140-1164. https://doi.org/10.1016/j.jpolmod.2018.05.002

Aloui, C., Hammoudeh, S., \& Hamida, H. Ben. (2015). Co-movement between sharia stocks and sukuk in the GCC markets: A time-frequency analysis. Comput Econ, 34, 69-79. https://doi.org/10.1016/j.intfin.2014.11.003

Anand, A., Li, T., Kurosaki, T., \& Kim, Y. S. (2016). Foster-Hart optimal portfolios. Journal of Banking and Finance, 68, 117-130. https://doi.org/10.1016/j.jbankfin.2016.03.011

Ben-Salha, O., Hkiri, B., \& Aloui, C. (2018). Sectoral energy consumption by source and output in the U.S.: New evidence from wavelet-based approach. Energy Economics, 72, 75-96. https://doi.org/10.1016/j.eneco.2018.03.029

Benlagha, N. (2014). Dependence structure between nominal and index-linked bond returns: A bivariate copula and DCC-GARCH approach. Applied Economics, 46(31), 3849-3860. https://doi.org/10.1080/00036846.2014.943886

Buchanan, B. G., English, P. C., \& Gordon, R. (2011). Emerging market benefits, investability and the rule of law. Emerging Markets Review, 12(1), 47-60. https://doi.org/10.1016/j.ememar.2010.09.001

Cascino, S. (2017). Stock-bond return co-movement and accounting information. Journal of Business Finance \& Accounting, 44(7-8), 1036-1072. https://doi.org/10.1111/jbfa.12253

Chen, M.-P., Chen, W.-Y., \& Tseng, T.-C. (2017). Co-movements of returns in the health care sectors from the US, UK, and Germany stock markets: Evidence from the continuous wavelet analyses. International Review of Economics and Finance, 49(1), 484-498. https://doi.org/10.1016/j.najef.2018.07.008

Chen, M. P., Chen, W. Y., \& Tseng, T. C. (2017). Co-movements of returns in the health care sectors from the US, UK, and Germany stock markets: Evidence from the continuous wavelet analyses. International Review of Economics and Finance, 49(July 2015), 484-498. https://doi.org/10.1016/j.iref.2017.02.009

el Alaoui, A. O., Dewandaru, G., Azhar Rosly, S., \& Masih, M. (2014). Linkages and co-movement between international stock market return: Case of Dow Jones Islamic Dubai Financial Market index. In Journal of International Financial Markets, Institutions and Money (Vol. 36). https://doi.org/10.1016/j.intfin.2014.12.004

Erdogan, O., Tata, K., Karahasan, B. C., \& Sengoz, M. H. (2013). Dynamics of the co-movement between stock and maritime markets. International Review of Economics and Finance, 25(2), 282-290. https://doi.org/10.1016/j.iref.2012.07.007

Faff, R. W., Hillier, D., \& Hillier, J. (2000). Time Varying Beta Risk: An Analysis of Alternative Modelling Techniques. Journal of Business Finance \& Accounting. https://doi.org/10.1111/1468-5957.00324

Graham, M., \& Nikkinen, J. (2011). Co-movement of the Finnish and international stock markets: A wavelet analysis. European Journal of Finance, 17(5-6), 409-425. https://doi.org/10.1080/1351847X.2010.543839

Hargis, K., \& Jianping, M. (2006). Is Country Diversification Still Better Than Sector Diversification? European Financial Management, 33(2), 319-340 Is. https://doi.org/10.2469/dig.v33.n2.1279

Hiang Liow, K. (2012). Co-movements and Correlations Across Asian Securitized Real Estate and Stock Markets. Real Estate Economics, 40(1), 97-129. https://doi.org/10.1111/j.1540-6229.2011.00314.x

Kallberg, J., \& Pasquariello, P. (2008). Time-series and cross-sectional excess comovement in stock indexes. Journal of Empirical Finance, 15(3), 481-502. https://doi.org/10.1016/j.jempfin.2007.06.002

Liow, K. H., \& Angela, S. Y. (2017). Return and co-movement of major public real estate markets during global financial crisis: A frequency domain approach. Journal of Property Investment and Finance, 35(5), 489_ 508. https://doi.org/10.1108/JPIF-01-2017-0002

Marfatia, H. A. (2017). A fresh look at integration of risks in the international stock markets: A wavelet approach. Review of Financial Economics, 34(1), 33-49. https://doi.org/10.1016/j.rfe.2017.07.003

Mensah, J. O., \& Premaratne, G. (2017). Dependence patterns among Asian banking sector stocks: A copula approach. Research in International Business and Finance, 41(April), 516-546. https://doi.org/10.1016/j.ribaf.2017.05.001 
Mensi, W., Hammoudeh, S., Al-Jarrah, I. M. W., Sensoy, A., \& Kang, S. H. (2017). Dynamic risk spillovers between gold, oil prices and conventional, sustainability and Islamic equity aggregates and sectors with portfolio implications. Energy Economics, 67, 454-475. https://doi.org/10.1016/j.eneco.2017.08.031

Mensi, W., Hammoudeh, S., \& Kang, S. H. (2017). Risk spillovers and portfolio management between developed and BRICS stock markets. North American Journal of Economics and Finance, 41, $133-155$. https://doi.org/10.1016/j.najef.2017.03.006

Mimouni, K., Charfeddine, L., \& Al-Azzam, M. (2016). Do oil producing countries offer international diversification benefits? Evidence from GCC countries. Economic Modelling, 57, 263-280. https://doi.org/10.1016/j.econmod.2016.05.001

Mohamed Dahir, A., Mahat, F., Ab Razak, N. H., \& Bany-Ariffin, A. N. (2018). Revisiting the dynamic relationship between exchange rates and stock prices in BRICS countries: A wavelet analysis. Borsa Istanbul Review, 18(2), 101-113. https://doi.org/10.1016/j.bir.2017.10.001

Pal, D., \& Mitra, S. K. (2019). Oil price and automobile stock return co-movement: A wavelet coherence analysis. Economic Modelling, 76(July 2018), 172-181. https://doi.org/10.1016/j.econmod.2018.07.028

Poynter, J. G., Winder, J. P., \& Tai, T. (2013). An analysis of co-movements in industrial sector indices over the last 30 years. Review of Quantitative Finance and Accounting, 44(1), 69-88. https://doi.org/10.1007/s11156-013-0399-z

Reboredo, J. C., \& Uddin, G. S. (2016). Do financial stress and policy uncertainty have an impact on the energy and metals markets? A quantile regression approach. International Review of Economics and Finance, 43, 284-298. https://doi.org/10.1016/j.iref.2015.10.043

Rehman, M. U., \& Shah, S. M. A. (2016). Determinants of Return's Co-Movement for Effective Portfolio Diversification Among Regional Stock Markets. Revista Evidenciação Contábil \& Finanças, 4(1), 84-96. https://doi.org/10.18405/recfin20160106

Sakemoto, R. (2018). Co-movement between equity and bond markets. International Review of Economics and Finance, 53(October 2017), 25-38. https://doi.org/10.1016/j.iref.2017.10.013

Shahzad, S. J. H., Ferrer, R., Hammoudeh, S., \& Jammazi, R. (2018). Industry-level determinants of the linkage between credit and stock markets. Applied Economics, 50(49), 5277-5301. https://doi.org/10.1080/00036846.2018.1486986

Shahzad, S. J. H., Nor, S. M., Sanusi, N. A., \& Kumar, R. R. (2017). The lead-lag relationship between US industry-level credit and stock markets. Journal of Economic Studies, 44(4), 518-539. https://doi.org/10.1108/JES-03-2016-0053

Souček, M. (2013). Crude oil, equity and gold futures open interest co-movements. Energy Economics, 40, 306-315. https://doi.org/10.1016/j.eneco.2013.07.010

Vacha, L., \& Barunik, J. (2012). Co-movement of energy commodities revisited: Evidence from wavelet coherence analysis. Energy Economics, 34(1), 241-247. https://doi.org/10.1016/j.eneco.2011.10.007 